\title{
The effect of sleep deprivation on sleep states, breathing events, peripheral chemoresponsiveness and arousal propensity in healthy 3 month old infants
}

\author{
D.A. Thomas*, K. Poole*, E.K. McArdle*, P.C. Goodenough*, J. Thompson**, \\ C.S. Beardsmore*, H. Simpson*
}

The effect of sleep deprivation on sleep states, breathing events, peripheral chemoresponsiveness and arousal propensity in healthy 3 month old infants. D.A. Thomas, $K$. Poole, E.K. McArdle, P.C. Goodenough, J. Thompson, C.S. Beardsmore, H. Simpson. (C)ERS Journals Ltd 1996.

ABSTRACT: We wished to investigate the effects of sleep deprivation on sleep, arousal propensity, respiratory events and peripheral chemoresponses in healthy infants, since these effects might be relevant to mechanisms concerned with some cases of sudden infant death syndrome.

Paired observations were made overnight during natural sleep and following sleep deprivation, in a randomized fashion, in 15 healthy infants aged 78 (7) days (mean (sD)). Polysomnograms were recorded and sleep was scored using Anders' criteria. Respiratory events were categorized into central, mixed and obstructive apnoeas. Peripheral chemoresponses were measured during quiet sleep from the respiratory response to two-breath alternations in fractional inspiratory oxygen $\left(F \mathrm{I}, \mathrm{O}_{2}\right)(0.42$ and 0.00). Arousal propensity was determined from awakening and arousal thresholds to graded photic and auditory stimuli during quiet sleep, and from spontaneous awakenings and limb movements.

Compared with natural sleep, following sleep deprivation infants maintained a greater proportion of quiet sleep (39 vs $44 \%$ ). There was no measurable change in arousal propensity. During quiet sleep, obstructed breathing events tended to be more common after sleep deprivation $\left(0.1\right.$ vs 0 events $\left.h^{-1}\right)$ and the expiratory time during baseline breathing increased significantly (1.27 vs $1.58 \mathrm{~s})$ although the decrease in respiratory rate was not significant $\left(32\right.$ vs 30 breaths' $\left.\mathrm{min}^{-1}\right)$. Peripheral chemoresponses altered significantly, alternations in tidal volume/inspiratory time $(V \mathrm{~T} / t \mathrm{I})$ as a measure of inspiratory drive increased after sleep deprivation $(9 \mathrm{vs} 21 \%)$.

In conclusion, following short-term sleep deprivation in infancy, respiratory control alters, peripheral chemoresponsiveness increases in magnitude and the timing of baseline breathing alters, without any detectable alteration in arousal propensity. This state may be associated with an increased vulnerability to obstructive respiratory events.

Eur Respir J., 1996, 9, 932-938.
Depts of *Child Health and **Ophthalmology, University of Leicester, Clinical Sciences Building, Leicester Royal Infirmary, Leicester, UK.

Correspondence: D. Thomas Department of Child Health Queens Medical Centre

Nottingham

NG7 2UH

UK

Keywords: Infant physiology peripheral chemoreceptors

respiration

sleep deprivation

Received: June 61995

Accepted after revision December 261995

Supported by a grant from the Foundation for the Study of Infant Deaths (project 155).
The effects of sleep deprivation on respiration and the control of breathing have been extensively investigated in adult humans. These include blunting of the ventilatory responses to hypoxia and hypercarbia [1], and an increase in the frequency and duration of obstructive apnoea in patients with adult sleep apnoea syndrome [2]. Sleep deprivation reduces the arousal propensity of adult dogs [3].

Sleep deprivation has been less fully studied in young infants. Effects comparable with those in adults might be relevant to the mechanisms thought to be concerned with some cases of sudden infant death syndrome (SIDS). Sleep deprivation in infancy increases the proportion of quiet sleep during subsequent sleep [4], and may increase apnoeas, particularly obstructive events, during active sleep [5]. Effects on ventilatory responses to hypoxia and arousal propensity have not, to our knowledge, been reported in infants. The latter has been described by
Phillipson [6] as "The forgotten response", and during infancy occurs in response to hypoxia and to obstruction of the upper airways. The aim of the present study was to assess the effects of short periods of evening sleep deprivation on sleep states, apnoeic events, ventilatory responses to hypoxia and arousal during quiet sleep in healthy 2-3 month old infants, during the night.

Subjects and methods

\section{Subjects}

Subjects were recruited from infants whose parents volunteered for the study in response to a news article in the local newspaper asking expectant mothers to contact us. 
Sixty three responded with expected dates of delivery between May and December 1992. A maximum of one infant per week was studied between July 1992 and February 1993. The infants were finally selected on the basis of sustained parental interest in the study when their infants were invited to attend at 10-12 weeks of age. Fifteen healthy infants of normal weight and height for age were studied, ( 8 girls and 7 boys) of mean (SD) weight $5.7(0.9) \mathrm{kg}$ and length 59 (3) $\mathrm{cm}$ at 78 (7) days of age. Their mean (SD) gestational age at birth was 40.4 (0.9) weeks and birth weight $3.6(0.57) \mathrm{kg}$. None had a history of respiratory or neurological disease. Detailed sleep histories were not taken, infants were not selected on the basis of sleep history, and none of the parents expressed concern regarding their infants' health or sleep patterns. Twelve infants were being breast-fed and three were exclusively bottle-fed. Thirteen usually slept in the supine position, one prone and the other on one side. Eight infants habitually slept in a cot in their parents bedroom and seven slept in a separate room. Four babies had a smoking parent.

\section{Study Design}

After a full explanation of the investigation, parents attended with their infants for two consecutive overnight studies (two infants were studied one night apart for parental convenience). Each infant was allowed to sleep naturally or after artificial sleep deprivation in a balanced randomized order. Parents were informed of the order of study after arrival on the first night. On natural sleep nights, infants were prepared for study and encouraged to follow their usual sleep pattern. On sleep deprivation nights, infants were kept awake, by preparation for study, play and tactile stimulation, for as long as possible beyond their habitual bedtime. Once asleep, polygraphic observations began. Infants slept supine in a cot, or if feasible their own cribs, and were fed on-demand during the study. Studies were conducted in an air-conditioned sleep laboratory at a mean (SD) ambient temperature of 22.4 (0.9) ${ }^{\circ} \mathrm{C}$, with illuminance levels of 3 lux and $65 \mathrm{~dB}$ background noise.

\section{Polygraphic monitoring}

The following electrophysiological signals were monitored: electroencephalogram (EEG) C4-A1 and O1-A2; electro-oculogram (EOG); submental electromyogram (EMG); and an electrocardiogram (ECG, lead II). After vigorous cleansing of the skin with an alcohol swab, silver-silver chloride electrodes were applied for EEG (10 mm disc electrodes; Meditec, Parma, Italy) with paste (Elephix; Nihon-Kohden, Tokyo, Japan). Similar electrodes for EOG and EMG (Miniature skin electrodes; Sensormedics, Anaheim, USA) were attached with adhesive collars and conductive gel (Medigel; Meditec, Parma, Italy). All electrode impedances were $7 \mathrm{ohms}$ or less at the start of recordings. "Mefix" adhesive tape (Molynyke Health Care AB, Sweden) was used to secure all electrodes.

Thoracic and abdominal respiratory movements were detected with strain gauges (Meditec, Parma, Italy), and airflow was monitored at both nares and the mouth by thermocouples (Type T 158-907; RS Components Ltd, Corby, UK). Respired gases were continuously monitored by means of a mass spectrometer (Airspec 2000, Biggin Hill, Kent, UK) via a catheter line, $1.5 \mathrm{~m}$ in length, taped carefully within the nares, sampling at a rate of 14.7 $\mathrm{mL} \cdot \mathrm{min}^{-1}$. Oxygen saturation was monitored with an Ohmeda Biox 3700e oximeter (Ohmeda, BOC, Hatfield, UK) set at a 3 s response time with a "Flex II probe" sensor sited across the lateral aspect of the left foot. Movements of the left foot were monitored using an accelerometer type movement detector (Meditec, Italy). Rectal temperature was recorded by means of an electronic thermometer (Model C, Edale Instruments, Cambridge, UK) with a matched rectal probe sited $5 \mathrm{~cm}$ from the anal margin. All these signals were recorded via isolation amplifiers on a computerized polygraph ("Sleeplab" CNS Inc., Minneapolis, USA). Additionally, infants wore thoracic and abdominal bands for respiratory inductance plethysmography (Model 150; Studley Data Systems, Oxford, UK).

\section{Protocol}

\section{Peripheral chemoresponses and arousal}

Electrophysiological signals were monitored continuously. During the first two or three cycles of quiet sleep, tests of peripheral chemoresponsiveness were conducted. After completion of the tests, arousal to auditory and photic stimuli was assessed at least 5 min into the next quiet sleep cycle. Infants then slept naturally for the remainder of the night and were fed on demand until they awoke after 6 a.m., at which point polygraphic recordings were stopped.

Peripheral chemoresponsiveness was determined from the breathing response to two breath alternations in fractional inspiratory oxygen $\left(F \mathrm{I}, \mathrm{O}_{2}\right)$, as described previously [7]. Briefly, breathing was monitored by means of respiratory inductance plethysmography (RIP), and the proportionality constant for thoracic and abdominal bands was derived for a Qualitative Diagnostic Calibration [8] at the beginning of the quiet sleep cycle. The respiratory pattern during two 2 min baseline periods breathing air was compared with that during a contiguous intervening test period breathing 42 and $0 \%$ oxygen in nitrogen in two-breath alternations. Gases were delivered via a facemask (Rusch size 3) held as close to the face as possible without contact. The inspired and end-tidal oxygen and carbon dioxide concentrations were continuously monitored by a mass spectrometer sampling at the nares. Inspired and expired tidal volume $(V \mathrm{~T})$, inspiratory and expiratory time $(t \mathrm{I}, t \mathrm{E})$ were measured and recorded and respiratory cycle time $t$ tot $(t$ tot $=t \mathrm{I} \times t \mathrm{E})$, inspiratory drive $(V \mathrm{~T} / t \mathrm{I})$, respiratory frequency $(1 / t$ tot $)$, inspiratory duty time $(t \mathrm{I} / t$ tot $)$ and instantaneous minute ventilation $(V \mathrm{~T} /$ $t$ tot) were computed for each breath. Consecutive second breaths of the two test gases were paired for analysis, and corresponding indices of ventilation identified. For each ventilatory index, the difference between paired values was expressed as a percentage of the mean values ("percentage alternations"). Results were expressed as the mean of these alternations for the test period, computed for each index of ventilation. 
Arousability was determined by the infants response to auditory and photic stimuli, applied for $5 \mathrm{~s}$ every $15 \mathrm{~s}$ at increasing intensity until either awakening occurred or the full sequence of stimulation had been applied. The nature and timing of each stimulus was marked on the polygraphic record. The auditory stimulus was a $1 \mathrm{kHz}$ pure tone from a signal generator (Wavetek model 144, San Diego, USA), which was delivered in the midline of the cot by a horn-type loudspeaker (RS Components 250-558, UK). The sound commenced at $73 \mathrm{~dB}$ and increased in $3 \mathrm{~dB}$ steps to $100 \mathrm{~dB}$, then recommenced at $73 \mathrm{~dB}$ as a fluctuating "warbling" signal with a $100 \mathrm{~ms}$ $2.4 \mathrm{kHz}$ sweep increasing in the same manner to $100 \mathrm{~dB}$. The photic stimulus was delivered by means of a digital stroboscope (Model EP 630; Eurisem, Earl Shilton, UK) held in the midline $50 \mathrm{~cm}$ from the face of the sleeping infant. The flash was of 188 Candela $\cdot \mathrm{m}^{-2} \cdot \mathrm{s}^{-2}$ and increased between 1.2 and $6.4 \mathrm{~Hz}$ in $0.4 \mathrm{~Hz}$ steps. Awakening was defined as generalized body movements, eyes opening or crying persisting for $15 \mathrm{~s}$.

\section{Analysis of records}

Sleep state was determined by one investigator (DAT) for each $30 \mathrm{~s}$ epoch using Anders' prime criteria [9]. The duration and frequency of left leg movements were scored manually and tabulated according to sleep state. Movements occurring within $10 \mathrm{~s}$ of each other were considered to be single events. Oximetry recordings were inspected and periods of artifactual recording, where the signal dropped to $0 \%$, were edited out and a record of this artifact time was made. The respiratory effort and airflow signals were inspected and scored manually. When airflow was absent for $6 \mathrm{~s}$ or more, an apnoea was recorded and categorized as central in the absence of any respiratory effort or obstructive if respiratory efforts continued. Mixed apnoea was recorded if both patterns were seen within an apnoeic event. Periodic breathing, defined as three or more central apnoeas of at least $3 \mathrm{~s}$ duration occurring within any $20 \mathrm{~s}$ period, was also identified. Apnoeas were never recorded when movements immediately preceded absence of the airflow signal.

Heart rate was recorded every $2 \mathrm{~s}$ and the heart rate variability was computed as the interquartile range of heart rate during each $30 \mathrm{~s}$ epoch individually for quiet and active sleep states. The means for each sleep state are reported.

The auditory and photic arousal sequences of the polygraph were inspected closely. Each sequence was divided into $15 \mathrm{~s}$ epochs coinciding with the cycles of the graded stimuli. The levels of stimulus at which the earliest sign of arousal and polygraphically confirmed awakening occurred were recorded using integers in inverse numerical scales, between 18 and 0 and 13 and 0 for successive auditory and photic stimuli, respectively. Awakening was defined for this purpose as body movements, eyes opening, crying or return of an awake EEG for at least $15 \mathrm{~s}$. Arousal was defined as any alpha wave intrusion, change from quiet sleep, $\mathrm{K}$-complex associated with the stimulus, disturbance in the cardiorespiratory pattern, or any movement. Spontaneous awakenings were recorded separately.

\section{Statistical analysis}

The effects of sleep deprivation and order of study were investigated separately utilizing analysis described for a two-period cross-over trial $[10,11]$. The effect of sleep deprivation on each observation was tested by calculating individual differences between the first and second night, and then comparing these differences for two study groups defined by the order of sleep deprivation. Parametric and nonparametric methods of comparison were used, t-test or Mann Whitney U-test, depending upon the normality of the data. Interactions between sleep deprivation and order effect were investigated by comparing the sum of observations (night $1+$ night 2) for the two groups. Analysis was implemented with Minitab (Minitab Inc., Pennsylvania, USA).

The study was approved by the Leicestershire Health Authority Ethics Committee.

\section{Results}

\section{Sleep deprivation}

On nights when the infants were sleep-deprived, the median onset of recording was 150 min later than on nights when they slept naturally (range 0-210 min). The time between the infants first appearing sleepy and being allowed to fall asleep was 94 (45-210) min, (median and range). Data for 14 paired polygraphic recordings are presented; in the remaining infant, the data were incomplete for technical reasons. Paired tests of chemoresponsiveness were available for eight infants.

\section{Sleep states}

The mean (SD) duration of all polygraphs was 493 (78) min, of which $432(80)$ min was sleep time. Table 1 gives the mean (SD) values for sleep time and the proportions of quiet, active and indeterminate sleep as percentages of sleep time on natural and post-deprivation nights. The total sleep time was similar on both nights. Quiet sleep accounted for a greater proportion of time asleep after sleep deprivation (44\%) than during natural sleep $(39 \%)(\mathrm{p}=0.02)$.

\section{Arousals}

Arousal propensity was assessed in terms of spontaneous wakenings, gross body movements, and the response

Table 1. - The effect of sleep-deprivation on sleep states $(n=14)$

\begin{tabular}{lrrrr}
\hline & \multicolumn{2}{c}{ Natural } & \multicolumn{3}{r}{ Sleep-deprivation } \\
\hline Sleep time min & 449 & $(97)$ & 414 & $(56)$ \\
Quiet sleep \% & 39 & $(5)$ & 44 & $(7)^{*}$ \\
Active sleep \% & 55 & $(8)$ & 50 & $(9)$ \\
Indeterminate sleep \% & 6 & $(5)$ & 6 & $(4)$
\end{tabular}

Values are presented as mean and SD in parenthesis. *: $\mathrm{p}=0.02$, between natural and post-deprivation values. 
Table 2. - The effect of sleep-deprivation on spontaneous movements and wakenings during sleep $(n=9)$

\begin{tabular}{|c|c|c|c|c|}
\hline \multirow[b]{2}{*}{ Wakenings $\mathrm{n}$} & \multicolumn{2}{|c|}{ Natural } & \multicolumn{2}{|c|}{ Post-deprivation } \\
\hline & 4 & $(0-12)$ & 2 & $(0-11)$ \\
\hline \multicolumn{5}{|c|}{ Movements $\mathrm{n} \cdot 100 \mathrm{~min}^{-1}$} \\
\hline QS & 13 & $(6-37)$ & 14 & $(5-24)$ \\
\hline AS & 45 & $(30-71)$ & 50 & $(36-57)$ \\
\hline Total sleep & 31 & $(23-52)$ & 33 & $(22-40)$ \\
\hline \multicolumn{5}{|l|}{ Movement time \%* } \\
\hline QS & 1.73 & $(0.04-6.91)$ & 1.48 & $(0.05-4.14)$ \\
\hline AS & 11 & $(0.27-48)$ & 14 & $(0.26-25.3)$ \\
\hline Total sleep & 7.9 & $(0.2-29.9)$ & 9.4 & $(0.2-16.6)$ \\
\hline
\end{tabular}

Values are presented as median, and range in parenthesis. *: Movement time is the total duration of movement as a percentage of sleep state. QS: quiet sleep; AS: active sleep.

to auditory and photic stimulation. Table 2 shows that spontaneous awakenings and the number and duration of movements were unaffected by sleep deprivation. Similarly, there were no changes in responsiveness to auditory or photic stimuli (table 3 ). Photic stimulation rarely resulted in arousal on either night.

\section{Respiratory events and arterial oxygen saturation}

Table 4 presents the median values for the indices of respiration and arterial saturation $\left(\mathrm{Sa}_{\mathrm{a}} \mathrm{O}_{2}\right)$. Central apnoeas, periodic breathing and $\mathrm{Sa}, \mathrm{O}_{2}$ were comparable on the two nights. A trend was observed toward an increased number of obstructive events (obstructive + mixed apnoeas) during non-REM (quiet + indeterminate sleep) ( $\mathrm{p}=0.09$, Mann-Whitney). Six infants had obstructive apnoeas during non-REM sleep only after sleep deprivation. Of the remaining eight infants, six had no obstructive apnoea on either night, one had obstructive apnoeas on both nights, and the remaining infant had obstructive apnoea on the natural sleep night.

\section{Heart rate variability of heart rate and temperature}

The mean heart rate during quiet sleep was 123 beats. $\min ^{-1}$ (bpm) on both nights; for active sleep the mean

Table 3. - Effect of sleep deprivation on induced arousals

\begin{tabular}{lcc}
\hline & Natural & Post-deprivation \\
\hline Infants aroused by sound $\mathrm{n}$ & $11 / 11$ & $11 / 11$ \\
Infants awakened by sound $\mathrm{n}$ & $9 / 11$ & $9 / 11$ \\
Auditory Arousal Threshold & $11(2-18)$ & $12(2-18)$ \\
Auditory Awakening Threshold & $7(0-17)$ & $8(0-16)$ \\
& & \\
Infants aroused by light n & $3 / 11$ & $1 / 11$ \\
Infants awakened by light $\mathrm{n}$ & $1 / 11$ & $1 / 11$ \\
Photic Arousal Threshold & $0(0-13)$ & $0(0-13)$ \\
Photic Awakening Threshold & $0(0-4)$ & $0(0-5)$ \\
\hline
\end{tabular}

The thresholds shown are median values (ranges) measured using inverse numerical scales $(0-13$ for photic and $0-18$ for auditory stimuli). Hence infants tended to arouse or waken to a quieter noise after sleep deprivation, though this was not significant.
(SD) values were 129 (12) bpm and 128 (10) bpm on natural and post-deprivation nights, respectively. There was a trend for heart rate variability to decrease after sleep deprivation from mean (SD) values of 6.4 (1.8) and 11.7 (2.6) bpm in quiet (QS) and active sleep (AS), respectively, to corresponding values of 5.8 (2.4) and 10.4 (3.2) bpm, but these changes did not reach statistical significance, $(\mathrm{p}=0.26$ for $\mathrm{QS} ; \mathrm{p}=0.11$ for $\mathrm{AS})$. Mean values for mean and lowest overnight rectal temperature were 36.6 and $36.4^{\circ} \mathrm{C}$ on both sleep-deprived and natural sleep nights $(\mathrm{p}=0.72$ for mean; $\mathrm{p}=0.97$ for lowest temperature).

\section{Respiratory pattern}

Figure 1 shows the effects of sleep deprivation, in each infant, on the various indices of ventilation measured during quiet sleep in the $2 \mathrm{~min}$ baseline periods prior to chemoresponse test periods. Mean expiratory time increased $(\mathrm{p}=0.03)$ and inspiratory duty time decreased $(t \mathrm{I} /$ $t$ tot $)(\mathrm{p}=0.04)$

\section{Peripheral chemoresponses}

Table 5 shows the effects of sleep deprivation on the means (SD) percentage alternations for each index of ventilation. The increase in inspiratory flow rate $(V \mathrm{~T} / \mathrm{t} \mathrm{I})$ alternations is shown in figure 2 and was significant ( $\mathrm{p}=0.048$ ). The trend toward increased alternations in $V \mathrm{~T}$ was not significant $(\mathrm{p}=0.10)$. Alternations of all other indices of ventilation were comparable on both nights.

Table 4. - Effect of sleep deprivation on respiratory events and oxygen saturation $(n=14)$

\begin{tabular}{|c|c|c|c|c|}
\hline & \multicolumn{2}{|c|}{ Natural } & \multicolumn{2}{|c|}{ Post-deprivation } \\
\hline \multicolumn{5}{|c|}{ Quiet and indeterminate sleep } \\
\hline \multicolumn{5}{|l|}{ Central apnoea } \\
\hline Index $\mathrm{n} \cdot \mathrm{h}^{-1}$ & 2.2 & $(0.3-12.2)$ & 2.2 & $(0.2-11.3)$ \\
\hline Time \% & 1.04( & $(0.13-7.59)$ & 0.85 & $0.08-7.77)$ \\
\hline \multicolumn{5}{|l|}{ Obstructive apnoea } \\
\hline Index $\mathrm{n} \cdot \mathrm{h}^{-1}$ & 0 & $(0-0.3)$ & 0.1 & $(0-0.6)$ \\
\hline Time \% & 0 & $(0-0.19)$ & 0.06 & $(0-0.39)$ \\
\hline \multicolumn{5}{|l|}{ Active sleep } \\
\hline \multicolumn{5}{|l|}{ Central apnoea } \\
\hline Index $n \cdot h^{-1}$ & 2.6 & $(0.1-8.9)$ & 2.4 & $(0-11.1)$ \\
\hline Time $\%$ & 1.06 & $(0.05-2.52)$ & 0.88 & $(0-11.8)$ \\
\hline \multicolumn{5}{|l|}{ Obstructive apnoea } \\
\hline Index $n \cdot h^{-1}$ & 0 & $(0-1.0)$ & 0 & $(0-7.5)$ \\
\hline Time $\%$ & 0 & $(0-0.6)$ & 0 & $(0-0.86)$ \\
\hline \multicolumn{5}{|l|}{ Periodic breathing } \\
\hline Index $\mathrm{n} \cdot \mathrm{h}^{-1}$ & 0.30 & $(0-20)$ & 0.25 & $(0-3.2)$ \\
\hline Time \% & 0.23 & $(0-5)$ & 0.23 & $(0-4.8)$ \\
\hline \multicolumn{5}{|l|}{ Oximetry } \\
\hline $\mathrm{Sa}_{\mathrm{a}, \mathrm{O}_{2}}$ baseline $\%$ & 97 & $(96-98)$ & 96 & $(95-98)$ \\
\hline
\end{tabular}

Values are presented as median, and range in parenthesis. Apnoea was defined as cessation of airflow for at least $6 \mathrm{~s}$. Apnoea index: number of events per hour; apnoea time: total duration of apnoea as $\%$ of sleep. Periodic breathing episodes were defined as three or more central apnoeas $>3 \mathrm{~s}$ within any $20 \mathrm{~s}$ epoch. $\mathrm{Sa}_{\mathrm{a}} \mathrm{O}_{2}$; arterial oxygen saturation. 

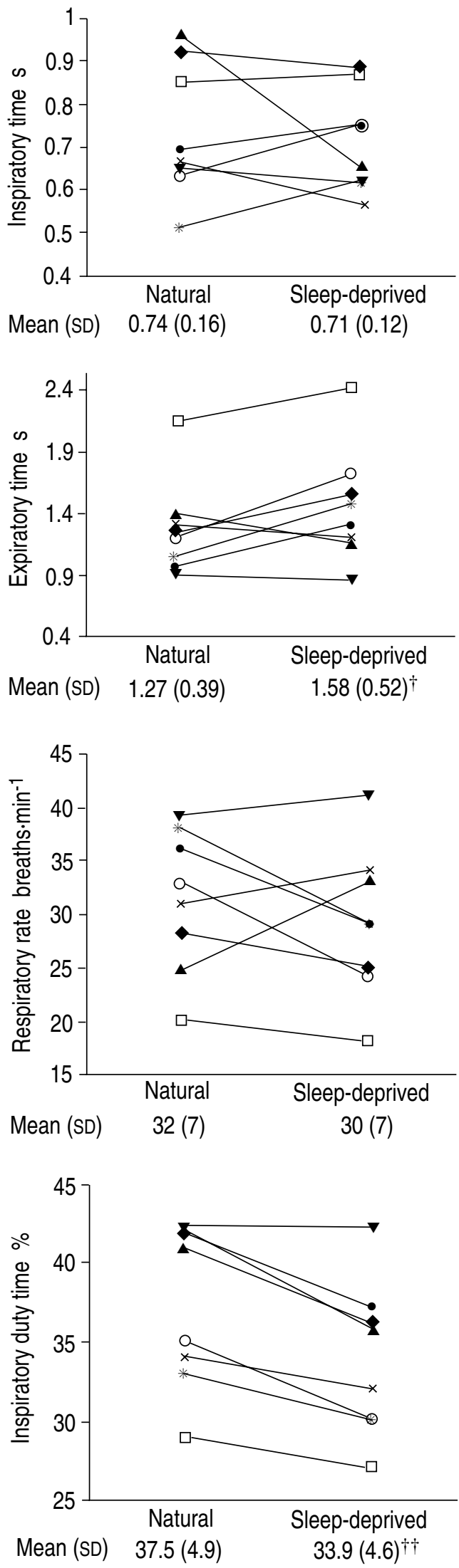

Fig. 1. - Effect of sleep deprivation on indices of ventilation measured during quiet sleep. Infant markers - $-\longrightarrow$ : No. 1; $-\longrightarrow$ : No. 2; $\neg$ : No. $3 ;-\square-$ : No. $4 ; \varangle$ : No. $5 ; \multimap$ * : No. $6 ;-\bigcirc-$ : No. 7 ; $\rightarrow$ : No. 8. ${ }^{\dagger},{ }^{\dagger \dagger}: \mathrm{p}<0.03,0.04$ (t-test).
Table 5. - The effect of sleep deprivation on the ventilatory response to alternating high (42\%) and low (0\%) inspired oxygen concentration $(n=8)$

\begin{tabular}{lcc}
\hline & Natural & $\begin{array}{c}\text { Post-deprivation } \\
\%\end{array}$ \\
\hline Tidal volume $(V \mathrm{~T})$ & 15.7 & 27.1 \\
& $(1.2-37.6)$ & $(5.37-71)$ \\
Inspiratory time $(t \mathrm{I})$ & 9.97 & 13.87 \\
& $(-8.6-25.03)$ & $(-2.99-40.93)$ \\
Expiratory time $(t \mathrm{E})$ & -9.35 & -12.69 \\
& $(-23.7-6.4)$ & $(-26.56-9.76)$ \\
Respiratory rate & -1.59 & 0.76 \\
& $(-3.8-11.42)$ & $(-7.83-9.5)$ \\
$V \mathrm{~T} / t \mathrm{I}$ & 9.13 & 21.00 \\
& $(-0.74-16.11)$ & $(2.36-43.74)^{*}$ \\
$t \mathrm{I} / t$ tot & 13.23 & 7.55 \\
& $(-8.57-20.68)$ & $(-4.87-45.69)$ \\
Instantaneous minute & 16.78 & 25.47 \\
ventilation $(V \mathrm{~T} / t$ tot $)$ & $(-0.74-33.88)$ & $(6.07-76.15)$ \\
\hline
\end{tabular}

Responses are median (ranges) of percentage alternations for each variable. $V \mathrm{~T} / t \mathrm{I}$ : inspiratory drive; $t \mathrm{t} / t$ tot: inspiratory duty time. *: $\mathrm{p}=0.048$ for $\mathrm{t}$-test ( $\mathrm{p}=0.06$ Mann-Whitney), between natural and post-deprivation values.

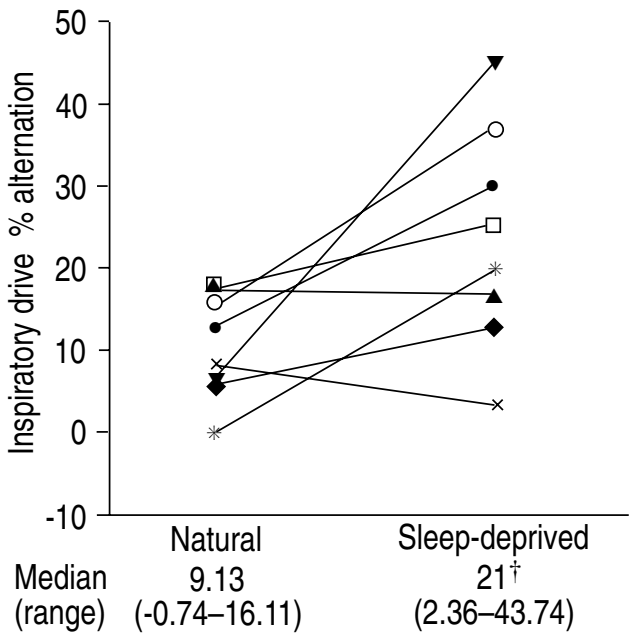

Fig. 2. - Effect of sleep deprivation on percentage alternations in inspiratory drive $(V \mathrm{~T} / \mathrm{t} \mathrm{I})$ during two-breath alternations in fractional inspiratory oxygen $\left(F \mathrm{I}, \mathrm{O}_{2}\right)$ between 0.00 and 0.42 . Results for individual infants are given by the same markers as in figure $1 . \dagger: \mathrm{p}=0.048$ (ttest) and $\mathrm{p}=0.06$ (Mann-Whitney), between natural and sleep-deprived.

\section{Discussion}

We have studied the effect of a relatively short period of nonselective sleep deprivation and subsequent catchup sleep in infants at night. This contrasts with other studies in which observations were made in awake sleepdeprived subjects [1], after selectively interrupting active or quiet sleep [4], during daytime sleep in infancy [5], and following longer periods of sleep deprivation [1]. The infants acted as their own controls, the study design and the analysis take into account the order effect.

The results show that following a brief period of sleep deprivation in 2-3 month old infants, during subsequent sleep there is an increase in the proportion of quiet sleep (QS), baseline respiratory patterns alter the increase in mean expiratory time and decrease in the inspiratory duty 
time $(t \mathrm{I} / t$ tot $)$ were both significant. Peripheral chemoreceptor responses alter, increasing in magnitude with respect to inspiratory drive $(V \mathrm{~T} / t \mathrm{I})$. The increased likelihood of obstructive respiratory events did not attain statistical significance. We found no effect on arousal propensity to visual or auditory stimuli, or on heart rate variability.

\section{Sleep}

Each infant was kept awake for as long as possible on the sleep-deprived night, without resorting to methods other than play and mild tactile stimulation. This resulted in infants falling asleep approximately one and a half hours later than usual. The increased proportion of quiet sleep during catch-up sleep confirms previous findings in adults and newborn infants $[4,5]$, and supports the view that the infants studied were significantly sleep-deprived. These observations in nonselectively sleep-deprived subjects suggest that quiet sleep is the "obligatory" part of sleep, with recuperative effects [12].

\section{Arousal propensity}

Simultaneous (same night) recordings of arousal propensity and peripheral chemoresponses were made in order to provide as complete a picture as possible of respiratory events following sleep deprivation. Spontaneous awakenings and movements were considered to best reflect the natural propensity to arouse from sleep. There was considerable variation among infants in this regard, with some remaining asleep throughout the study period, whilst others awoke on several occasions. Similarly, spontaneous movements varied markedly among the infants studied, but no differences were observed between natural and sleep-deprived nights. Newman et al. [13] investigated developmental changes in arousal thresholds to vibrational stimuli during the first 6 months of life, and reported a reversible increase in failure to arouse from all stages of sleep at 3 months. In the present study, the infants were remarkably refractory to the stimuli applied even during natural sleep nights. Photic stimuli rarely caused arousal, perhaps because of upward deviation of the eyes during sleep; and auditory stimuli failed to arouse most infants despite the intensity of the auditory signal. We did not assess arousal to respiratory stimuli, either by obstructing the upper airway or by hypoxic or hypercapnic stimulation. Three month old infants require a considerable degree of hypoxia to provoke arousal, whereas arousal to hypercapnia occurs with relatively smaller changes $[14,15]$.

\section{Apnoea}

Respiratory events were tabulated according to type and sleep state. Indices of central apnoea were comparable with previously published data for healthy infants of a similar age [16], with no change following sleep deprivation. We chose a minimum duration of $6 \mathrm{~s}$ for respiratory events, as we considered that changes of this order might best detect early changes in respiratory control. There was a trend towards an increase in obstructive respiratory events when quiet and indeterminate sleep were considered together, though this was not statistically significant $(\mathrm{p}=0.09)$ even when the infants of a smoking parent were considered separately. This is in apparent contrast to the observations of CANET et al. [5], who found statistically significant increases in the number and duration of all respiratory pauses during sleep, particularly obstructive events during active sleep. This may have been the result of methodological differences. Our subjects were 3 months old, whereas those studied by CANET et al. [5] were aged between 1-6 months. We defined apnoea as an absence of airflow for at least $6 \mathrm{~s}$, whereas pauses of 3-6 s were included by CANET et al. [5]. We did not record apnoea when movements immediately preceded absence of the airflow signal. Finally, our studies were conducted during the night and were of longer duration.

\section{Respiratory control}

Sleep deprivation affected baseline breathing patterns during quiet sleep. Respiratory rate did not change significantly but expiratory time and inspiratory flow rate did, suggesting a change in respiratory control. A decrease in minute ventilation and increased respiratory rate during active sleep have been reported following selective sleep deprivation in adults [17], but have not been confirmed in other reports [18]. Our observations were confined to quiet sleep and are, therefore, not comparable with previously published data.

The ventilatory response to two-breath alternations in $F \mathrm{I}, \mathrm{O}_{2}$ was utilized to measure the peripheral chemoresponse. This method reliably causes a large relatively rapid alternation in end-tidal oxygen concentration without significant effect on end-tidal carbon dioxide concentrations and, hence, is a measure of peripheral chemoresponsiveness to oxygen [7]. The effect of sleep deprivation on peripheral chemoresponses was somewhat surprising. We observed a significant increase in respiratory drive $(V \mathrm{~T} /$ $t \mathrm{I})$ despite the relatively small number of infants studied. In adults, WHITE et al. [1] reported a decrease in hypoxic ventilatory response in subjects studied awake after a night of complete sleep deprivation; others have not confirmed these findings [17]. Our studies in infants are not directly comparable with those in adults and there are no infant data showing the effect of more prolonged sleep deprivation on respiratory control. Conceivably, an initial increase might be superceded by blunted responsiveness if sleep deprivation were prolonged.

\section{Possible relevance to SIDS}

It is tempting to speculate that our findings may be relevant to SIDS, which occurs mainly during the night at a peak age of 2-3 months [19]. The incidence is increased at weekends and at times of family disruption [20]. Pathological evidence supports the view that terminal breathing events in SIDS victims are of an obstructive nature [21] and that, in some instances at least, there are changes in carotid body content consistent with blunted ventilatory and arousal responses to hypoxia during life [22]. There is also evidence from polygraphic studies that obstructive breathing events may antecede the occurrence of SIDS [23]. Blunted hypoxic ventilatory and arousal 
responses have also been reported in infants following apparently life threatening events (ALTEs) [24].

In recent years, sleeping position has been the main focus of attention and the dangers of prone sleeping are now fully recognized [25]. Whether infants who died during sleep in the prone position had additional vulnerability is unknown. Any propensity to obstructive respiratory events, with altered ventilatory responses and reduced arousal propensity would almost certainly render infants more vulnerable. During inspiration, the natural tendency of the upper airway to collapse due to the suction effect of the diaphragm is counteracted by phasic tonic contraction within dilating muscles of the upper airway [26]. Reflex effects favouring upper airway patency under adverse conditions include the preferential increase in upper airway dilating muscle tone compared with diaphragmatic activity in response to chemical stimuli and a decrease in diaphragmatic activity observed in infants responding to reduced pressure within the oropharynx [27]. An increase in respiratory drive, such as seen in the present study in response to hypoxia following sleep deprivation, may conceivably produce a suction effect, thereby increasing the likelihood of upper airways obstruction, particularly if associated with a reduction in airway maintaining muscle tone [28].

In conclusion, in infants aged 3 months following sleep deprivation there is an increase in the relative amount of quiet sleep, during which there are alterations in the breathing pattern (increased expiratory time and decreased inspiratory duty time) and of peripheral chemoresponses (increased inspiratory drive $V \mathrm{~T} / T \mathrm{I}$ ). These changes in respiratory pattern and control might contribute to an increased propensity to upper airway obstruction after sleep deprivation, particularly if associated with a reduction in upper airway tone.

Acknowledgements: The authors thank the Foundation for the Study of Infant Deaths for generous financial support and all the families who participated in this study. They would also like to thank M.A. Hanson and P. Kumar for their generous support and encouragement, the loan of equipment and gift of software.

\section{References}

1. White DP, Douglas NJ, Pickett CK, Zwillich CW, Weil JV. Sleep deprivation and the control of ventilation. $A m$ Rev Respir Dis 1983; 128: 984-986.

2. Guilleminault C. Sleep apnea syndromes: impact of sleep and sleep states. Sleep 1980; 3: 227-234.

3. Phillipson EA, Bowes G, Sullivan CE, Woolf GM. The influence of sleep fragmentation on arousal and ventilatory responses to respiratory stimuli. Sleep 1980; 3: 281-288.

4. Anders TF, Roffwarg HP. The effect of selective interruption and deprivation of sleep in the human newborn. Dev Psychobiol 1973; 6: 77-89.

5. Canet E, Gaultier C, D'Allest A-M, Dehan M. Effects of sleep deprivation on respiratory events during sleep in healthy infants. J Appl Physiol 1989; 66: 1158-1163.

6. Philipson EA. Arousal: The forgotten response to respiratory stimuli. Am Rev Respir Dis 1978; 118: 807-809.

7. Thomas DA, Poole K, McArdle EK, et al. Peripheral chemoresponses of infants measured by a minimally invasive method utilising two-breath alternations in $\mathrm{F}_{\mathrm{I}}, \mathrm{O}_{2}$. In press.
8. Sackner MA, Watson H, Belsito AS, et al. Calibration of respiratory inductive plethysmography during natural breathing. J Appl Physiol 1989; 66: 410-420.

9. Anders T, Emde R, Parmelee A. A manual for standardized terminology and criteria for scoring of states of sleep and wakefulness in newborn infants. Los Angeles, UCLA Brain Information Service, 1971.

10. Hills M, Armitage P. The two-period cross-over clinical trial. Br J Clin Pharmacol 1979; 8: 7-20.

11. Mann W, Jones B, Kenward MG. Design and analysis of cross-over trials. London, Chapman \& Hall, 1989.

12. Horne JA. Sleep function with particular reference to sleep deprivation. Ann Clin Res 1985; 17: 199-208.

13. Newman NM, Trinder JA, Phillips KA, Jordan K, Cruickshank J. Arousal deficit: mechanism of the sudden infant death syndrome? Aust Paediatr J 1989; 25: 196-201.

14. Berthon-Jones M, Sullivan CE. Ventilatory and arousal responses to hypoxia in sleeping humans. Am Rev Respir Dis 1982; 12: 286-289.

15. Davidson-Ward SL, Bautista DB, Keens TG. Hypoxic arousal responses in normal infants. Pediatr Pulmon 1989; 7: 276A.

16. Guilleminault C, Ariagno R, Korobkin R, Nagel L, Coons S, Owen M. Mixed and obstructive apnea and near miss for sudden infant death syndrome: 2. Comparison of near miss and normal control infants by age. Pediatrics 1979; 64: 882-891.

17. Neilly JB, Kribbs NB. Effects of selective sleep deprivation on ventilation during recovery sleep in normal humans. J Appl Physiol 1992; 72(1): 100-109.

18. Horne JA. The effects of sleep deprivation upon variations in heart rate and respiration rate. Experientia 1977; 33: $1175-1176$

19. Bergman AB. SIDS in King County, Washington: epidemiological aspects. In: SIDS, eds. A.B. Bergman, J.B. Beckwith, C.G. Ray. University of Washington Press. 1970; p. 49.

20. Emery JL. Epidemiology of "sudden, unexpected or rapid" deaths in children. $B r$ Med $J$ 1959; 2: 925.

21. Beckwith JB. Intrathoracic petechial haemorrhage: a clue to the mechanism of death in sudden infant death syndrome? Ann NY Acad Sci 1988; 533: 37-47.

22. Perrin D, Cutz E, Becker L, Bryan A, Madapallinatum A, Sole M. Sudden infant death syndrome: increased carotid body dopamine and noradrenalin content. Lancet 1984; ii: 535-537

23. Kahn A, Blum D, Rebuffat E, et al. Polysomnographic studies of infants who subsequently died of sudden infant death syndrome. Pediatrics 1988; 82: 721-727.

24. van der Hal A, Rodriguez A, Sargent C, Platzker A, Keens T. Hypoxic and hypercarbic arousal responses and prediction of susequent apnea in apnea of infancy. Pediatrics 1985; 75: 848-854.

25. Fleming PJ, Gilbert R, Azaz Y, et al. Interaction between bedding and sleeping position in the sudden infant death syndrome: a population based case-control study. $\mathrm{Br}$ Med J 1990; 301: 85-89.

26. Roberts JL, Reed WR, Mathew OP, Thach BT. Control of respiratory activity of the genioglossus muscle in micrognathic infants. J Appl Physiol 1986; 61: 1523-1533.

27. Mathew OP, Abu-Osba UK, Thach BT. Influence of upper airway pressure changes on genioglossal muscle respiratory activity. J Appl Physiol: Respirat Environ Exercise Physiol 1982; 52: 438-444.

28. Leiter JC, Knuth SL, Bartlett D Jr. The effect of sleep deprivation on activity of the genioglossus muscle. Am Rev Respir Dis 1985; 132: 1242-1245. 